\title{
EVALUATION OF NURSING EDUCATION FOR STUDENTS BASED ON ANALYTIC HIERARCHY PROCESS
}

\author{
Sang Suk Kim \\ Red Cross College of Nursing \\ Chung-Ang University \\ Seoul, South Korea \\ E-mail: kss0530@cau.ac.kr
}

\begin{abstract}
This paper presents a nursing evaluation methodology for undergraduate students. To enhance educational effect for training nursing students, faculties of college of nursing develop number of methodology such as Simulation, Standard patient, and Virtual patient etc.. Even though each methodology can obtain good results in a certain viewpoint, but obtain side effects also. So this paper focused on the basic model which can evaluate a methodology for its results. Because this study is a start of nursing education evaluation, this paper presents a methodology only.
\end{abstract}

Keywords: Evaluation, Nursing Education, Student Training, Simulation

\section{Introduction}

Many nursing school in Korea do evaluate effects of nursing education. As a methodology, researchers obtain answers of question from students who finished education, and analyze by using quantitative and qualitative methodology. This methodology has merit to obtain analyzing result for specified field only, but has limitations for overall evaluation.

This paper employed Analytic Hierarchy Process methodology and build a model which can evaluate overall fields of nursing education. First, author proposes the use of three states to measure effects of nursing education, such as [Ideal Achievement], [Actual Achievement], and [No Achievement]. Second, this paper proposes a methodology to rescale [Actual] states instead of employing one-to-one matrices. This methodology can rescale them to fit human judgment. Finally, this paper presents an Analytic Hierarchy Process(AHP) model to obtain an absolute achievement using eigenvalue analysis. By using the proposed methodology, author can specialize for evaluation of nursing education. 


\section{Review of Korean Nursing Education Evaluation}

Nowadays, Korean nursing school do education as follows:

(1) Problem-based Learning(PBL)

(2) Team-based Learning(TBL)

(3) Simulation

(4) Standard Patient(SP)

(5) Micro Simulation

Because each education methodology has good point and weak point, evaluator has difficulties to evaluate the overall effect of nursing education.

\section{Evaluation of Nursing Education by using AHP}

\subsection{Ideal Analytic Hierarchy Process}

To overall evaluate for a system, Ideal AHP was developed, and authors employed it. Ideal AHP has [Ideal] - [Actual] - [Possible] States, and showed as follows:

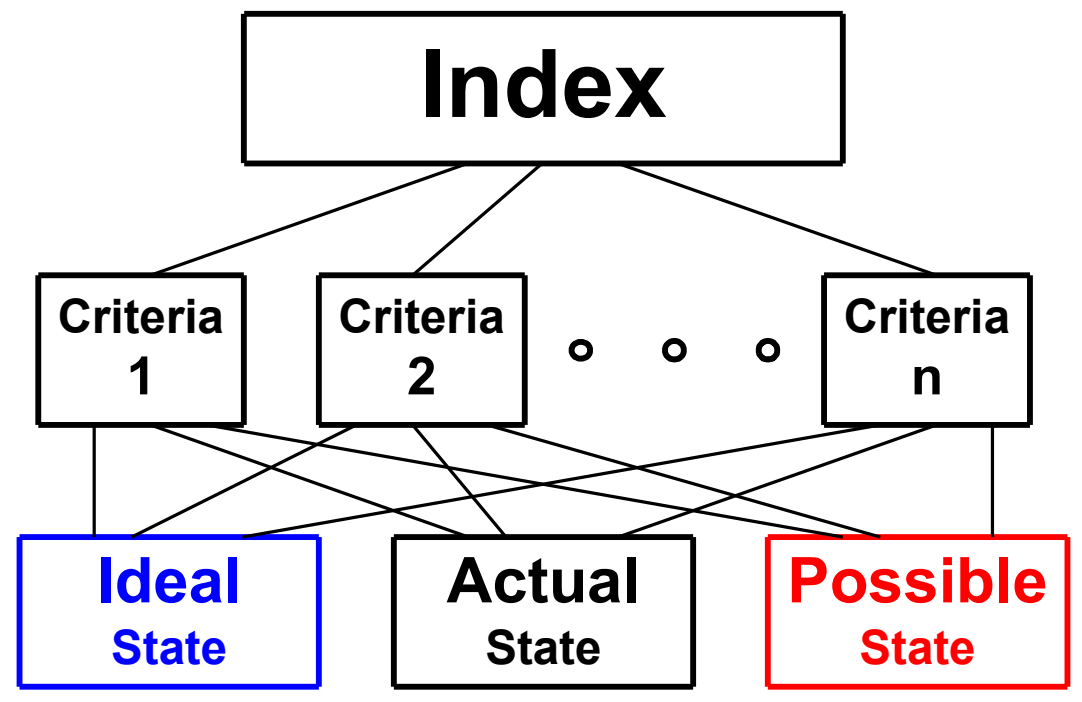

Fig. 1. Ideal AHP

\subsection{Application of Nursing Education}

This paper propose an application model for nursing education which has [Ideal Achievement], [Actual Achievement], and [No Achievement] for Alternatives, and Student achievements and understandings for Criteria. Concept of the model as follows: 


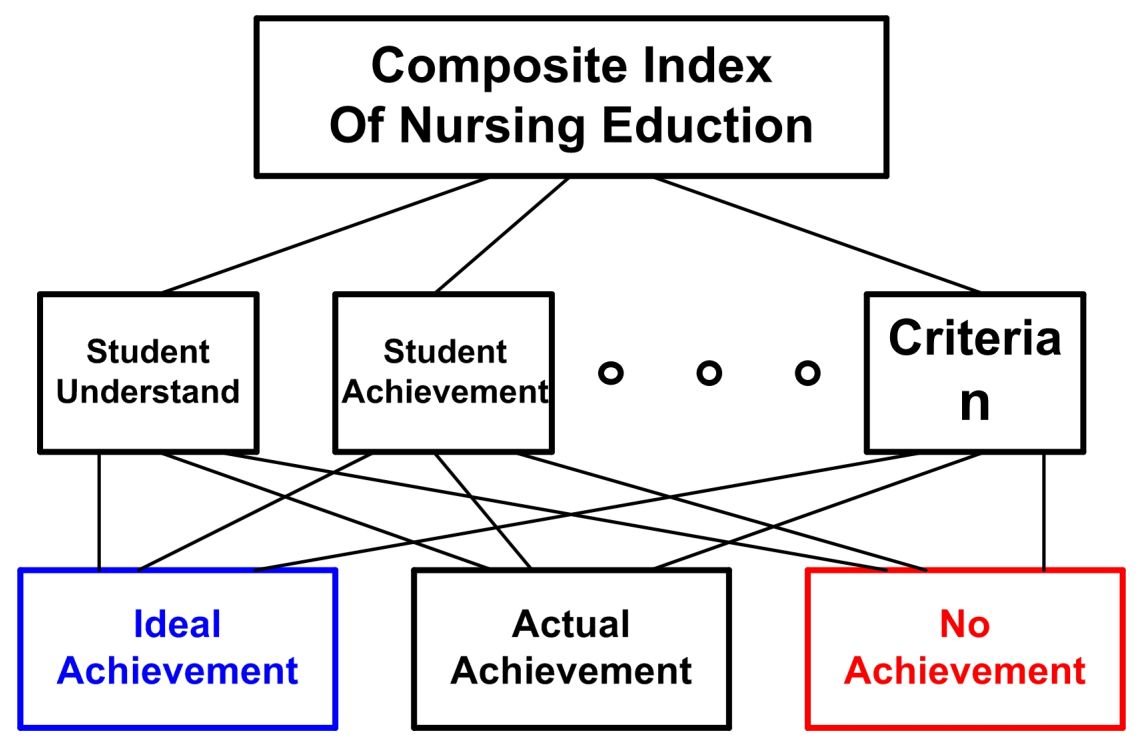

Fig. 2. Developed AHP Model

\section{Conclusions}

This paper employed Ideal Analytic Hierarchy Process, and applied it to the evaluation of nursing education of nursing school of Korea. By this methodology, authors can obtain overall evaluation index for achievement of nursing education.

\section{Key References}

Thomas L. Satty, "The Analytic Network Process", RWS Publications, 1996

Marija D. Ilic et al., "Hierarchical Power Systems Control - Its Value in a Changing Industry", Springer, 1996

Ernest Forman, "Decision by Objectives", http://mdm.gwu.edu/forman

B. Lee, "Unified Power Quality Index using Ideal AHP", ICHQP, July, 2008

Kang, I. A., "The theory and practice of PBL”. Seoul, 2003. 